\title{
MODELING THE RESPONSE OF A PLANAR SILICON DETECTOR WHEN MEASURING THE EXPOSURE DOSE RATE IN THE ENERGY RANGE FROM $5 \mathrm{keV}$ TO $10 \mathrm{MeV}$
}

\author{
V. N. Dubina*, N.I. Maslov, I. N. Shlyahov \\ National Science Center "Kharkiv Institute of Physics and Technology", 61108 Kharkiv, Ukraine
}

(Received July 8, 2020)

\begin{abstract}
The main advantages of using silicon semiconductor detectors in dosimetry in comparison with traditional detectors are considered. The shortcomings are analyzed and possible methods for their elimination are proposed. One of the proposed methods makes it possible to increase the efficiency of detecting gamma quantum in the energy range $0.1 \ldots 10 \mathrm{MeV}$. The requirements are formulated to optimize the design of detectors operating in a wide range of dose rates and gamma radiation energies by computer simulation. Mathematical calculations and computer simulations determine the dosimeter design, materials and thicknesses $\gamma$-converter. The mechanisms of modeling the absorbed dose in air and ambient dose in silicon detectors with a thickness of $300 \mu \mathrm{m}$, sizes $(5 \times 5) \mathrm{mm}^{2}$ and $(1.8 \times 1.8) \mathrm{mm}^{2}$, in the range of incident $\gamma$-ray energies from $5 \mathrm{keV}$ to $10 \mathrm{MeV}$ are presented.
\end{abstract}

PACS: 03.65.Pm, 03.65.Ge, 61.80.Mk

\section{INTRODUCTION}

Modern industry produces a large number of gamma radiation dosimeters, however, their error reaches tens of percent, and the working interval of energies, as a rule, does not go beyond the range of $50 \mathrm{keV} \mathrm{\ldots 3} \mathrm{MeV}$. Based on the experience [1, 2], it is possible to expand this range to some of $\mathrm{keV}$. This expansion is in particular associated with the study of secondary radiation, which tends to be redistributed to extremely low energies [3]. Improving the accuracy of dosimeteric measurements and expanding the reduced interval continues to be a fairly urgent task. To detect a $\gamma$-quantum, it is necessary to register its interaction with the medium. Gamma radiation is characterized by a large penetrating and weak ionizing ability. Gamma-ionization of the medium is carried out by means of secondary electrons (photoelectric effect, Compton-effect, pair production). The charge released in is an electric impulse, the amplitude of which is proportional to the energy lost by the photon. The use of semiconductor detectors for measuring absorbed and exposure doses is limited by the absence of a direct dependence of dose sensitivity on the energy of incident radiation. The results of computer simulation of the assembly, as well as a change in the level of discrimination of incoming pulses show possible ways to create "flat response" for the wide energy range. The requirement for modern dosimeters is to be universal in work in any radiation field. Such requirements, in fact, do not imply the determination of absorbed energy, but the restoration of the primary flux entering the detector. But the natu- ral requirement could be equalization of the response to equal energy flows, which actually determine the degree of impact on the object, in particular on the biological one. From another hand the transmitted part of the energy directly depends on the energy of the primary particle. In the extremely case of complete absorption, the response for any energy flow will be the same. With a decrease in the thickness of the detector, part of the energy left in the detector will decrease more with increasing energy of gammaquantum due to a decrease in the cross section for energy transfer to matter and an increase in the yield of delta electrons (see Fig.7). Due to this, it is precisely possible to equalize the response of the detectors in a wide range of gamma-ray energies with identical primary flows.

\section{EXPOSURE DOSES}

The characteristic of the exposure dose is exhaustively expressed by the number of ion pairs in the air, under normal conditions, corresponding to either $1 C / \mathrm{kg}$ or the most affordable $1 R$, corresponding to $87.3 \mathrm{erg} / \mathrm{gram}$ or $2.08 \cdot 10^{9}$ ion pairs in $\mathrm{cm}^{3}$. For photon energy of $100 \mathrm{keV}$, this corresponds to a flux of $1.97 \cdot 10^{10}$ per $\mathrm{cm}^{2}$ or $4.2 \cdot 10^{11}$ for energy of gamma-rays of $10 \mathrm{MeV}$. As a rule, recalculation of detector readings is traditionally given in units of the exposure dose, which can create additional difficulties when working in the counting mode. Fig.1 shows the results of modeling the absorbed energy in the energy range $30 \mathrm{keV} \ldots 10 \mathrm{MeV}$ for air and silicon. Fig.1 shows good agreement in the energy range $100 \mathrm{keV} \ldots 2 \mathrm{MeV}$. For low energies, there is

\footnotetext{
${ }^{*}$ Corresponding author E-mail address: dubinavn@kipt.kharkov.ua
} 
an excess due to large cross sections of the photoelectric effect in silicon. For high energies, a decrease in absorption in air is observed due to the escape of secondary particles from the energy deposited region. Thus, equalization of the sensitivity of the simulated detector for energies above $2 \mathrm{MeV}$ will lead to the accumulation of error when using the exposure dose as standard. In the future, it is supposed to evaluate this error depending on the thickness of the detector and filters, leading to additional scattering and a decrease in the primary energy of the quantum. When the detector operates in an energy range of less than $100 \mathrm{keV}$, it is proposed to apply additional technical solutions. For the energies above $2 \mathrm{MeV}$, conversion to exposure dose units leads to the accumulation of errors associated with the different nature of the interaction of gamma quanta with silicon and the formation of ion pairs in air. In particular, the exposure dose may correspond to much higher than these values at the same flows, the absorption of energy in silicon.

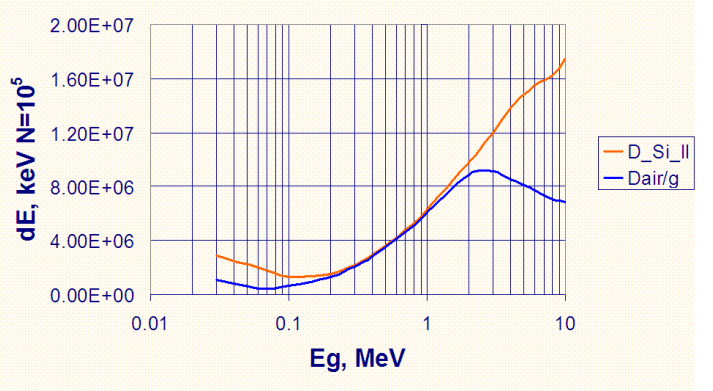

Fig.1. The dependence of the absorbed energy in silicon and air on the primary radiation energy

Silicon detectors developed and created at the NSC KIPT are widely used in nuclear physics experiments $[1,2]$, in medical diagnostic studies, and in the field of radiation safety $[3,4]$. The development of the detector in a universal sealed enclosure is presented in $[5,6]$

\section{ENERGY DEPOSITION CALCULATION DEPENDS ON GAMMA QUANTUM PRIMERY ENERGY}

According to definition of the absorbed dose, this is the energy transferred to a unit mass of a substance, i.e. $D=E_{a b s} / m$. The absorbed dose is measured in Gy. $1 \mathrm{~Gy}=100 \mathrm{rad}=6.24 \cdot 10^{9} \mathrm{MeV} / \mathrm{g}$. The absorbed dose created by the flux of monochromatic $\gamma$-quanta is determined by the formula:

$$
D=\Phi_{\gamma} E_{\gamma} \mu_{e n} t
$$

where $\Phi_{\gamma}$ - is the radiation flux density, $\mathrm{cm}^{-2} ; E_{\gamma}-$ is the energy of the $\gamma$-quantum, erg; $\mu_{e n}-$ is the mass coefficient of energy absorption, $\mathrm{cm}^{2} / \mathrm{g}$. The formula is valid to the extent that the thickness of the detector is much less than the mean free path of the particle.

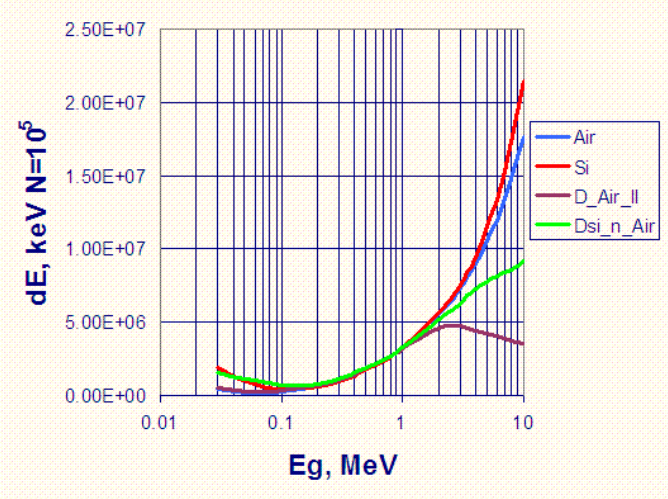

Fig.2. Comparison of analytical calculations (1) with simulation results. The red curve is the calculation for silicon; the blue curve is the calculation for air. Green curve - sensitivity modeling in silicon. Brown - simulation of the exposure dose

Fig.2 shows the distributions of sensitivities in the energy range of $30 \mathrm{keV} \ldots 10 \mathrm{MeV}$, calculated by the formula (1), and also modeled by the computer model "Doze ${ }_{X}$ ", developed using the Geant.4.9.1 software module based on taking to account of real geometry and secondary particles balance. Calculations and simulations give good agreement in the energy range up to $2 \mathrm{MeV}$. The accuracy of determining the absorbed energy according to (1) is usually the greater then greater the ratio of primary energy / thickness of the sensitive layer, but it is in the high energy range that a significant discrepancy is observed. This is primarily due to the fact that the greater the energy of primary radiation creates the correspondingly secondary particles with greater the energy too. In particular, due to the departure of delta electrons and high-energy secondary gammarays primary deposited energy are removing from the volume under study. On the other hand, the scatterer with the bigger $\mathrm{Z}$ is absorbing more secondary radiation. In order to analyze the differences in absorption in different media at maximum energies, the detector responses to the primary gamma-ray energy of $10 \mathrm{MeV}$ were modeled. Fig.3 presents the results of modeling by the "Doze $X$ " program the energy release (Energy Deposition) of transmitted radiation with a primary energy of $10 \mathrm{MeV}$.

At high primary radiation energies or correspondingly small target thicknesses, small energy losses of the order of several keV are most likely (see Fig.3). Differences of energy losses distributions in silicon and in air are determined by the difference in $\mathrm{Z}$, which creates a wider range of energy losses. The second maximum in the loss distribution is located in the case of silicon in the range up to $100 \mathrm{keV}$ (see Fig.3, a). For air, such a maximum is limited to a range of $40 \mathrm{keV}$. In the range of more than $60 \mathrm{keV}$, there is a monotonous decrease in energy losses, which generally extend to units of $\mathrm{MeV}$ for silicon and almost completely disappears to $1 \mathrm{MeV}$ for air. (see Figs.3, a, b). It can be assumed that 
this effect determines the behavior of the sensitivity curves for these media in the high-energy range.

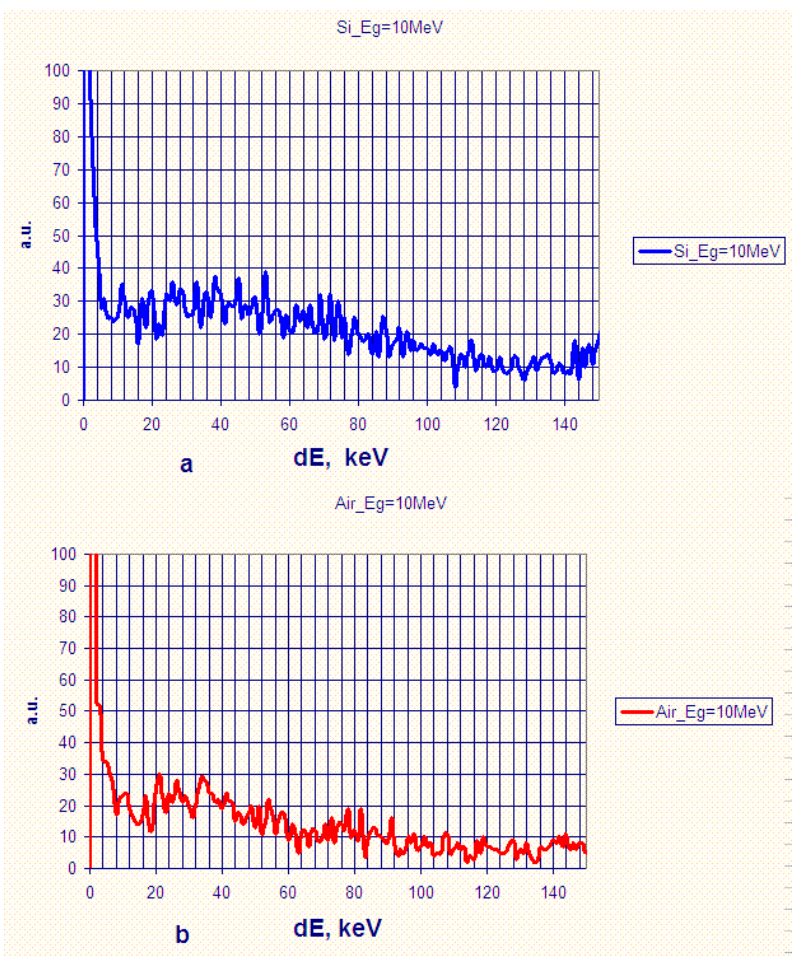

Fig.3. Modeling the response of a silicon detector with the "Doze ${ }_{X}$ " program in the form of the spectral distribution of absorbed energy during the passage of high-energy gamma-rays through silicon (a) and air (б)

\section{OPTIMIZATION OF DETECTOR GEOMETRY}

Thus, the requirement of matching the detector sensitivity with air (i.e., matching with exposure dose) is confronted with various types of energy deposition, in particular at high energies. And if the requirement for absorption in a gram of dry air is unchanged, then, by varying the thickness of the detector, a change, alignment of the sensitivity of the silicon detector is possible.

In Fig. 4 shows the distribution of the dependence of sensitivity on energy for a silicon detector with different thicknesses of the sensitive layer. Fig.4 shows that at low energies, the sensitivity weakly depends on the thickness. As the primary energy of the gamma quantum increases, the influence of the detector thickness on the response flatness increases. So, if for curve corresponding to $500 \mu \mathrm{m}$, in the energy range above $100 \mathrm{keV}$, the sensitivity deviation is $35 \%$ (brown curve), then for a thickness of $300 \mu \mathrm{m}$ this is already reduced to $25 \%$ (orange curve). Thus, for certain silicon thickness, it is possible to optimize the correspondence of the detector response to the exposure dose over wide energy range.

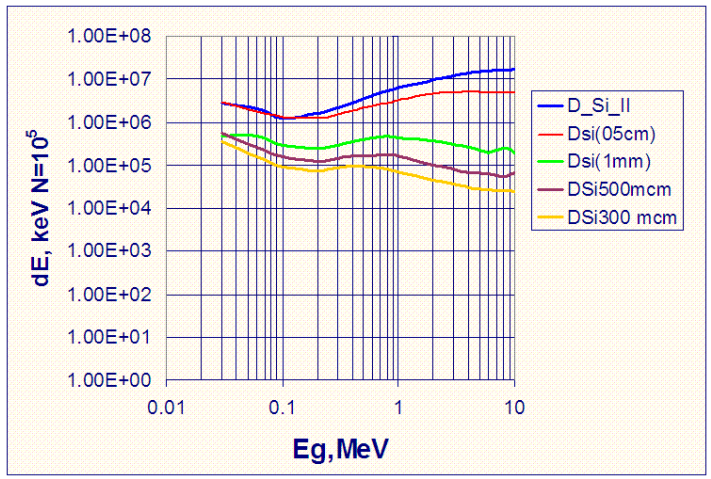

Fig.4. Dependence of sensitive layer thickness on detector sensitivity, calculated in the direction of radiation propagation

Reducing the thickness of the detector decreases the overall efficiency of recording the radiation flux. To increase (align) the response, it is also possible to use a substrate with a high reflection scattering coefficient, especially for secondary radiation.

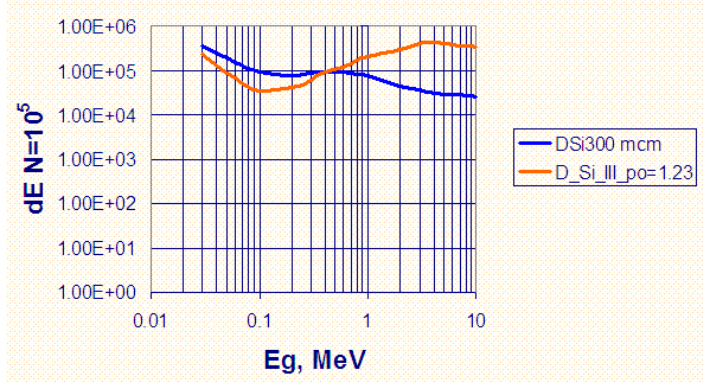

Fig.5. Detector design influence on the distribution of dose sensitivity. Red curve - with screen $C$ $10 \mathrm{~mm}$, blue - without screen

Fig.5 shows various effects of optimizing the environment of the detector sensitive layer. The red curve shows the case when, with the same thickness of the silicon detector $-300 \mu \mathrm{m}$, an increase in sensitivity in the high energy range is possible due to the addition of a diffuser screen made of light materials of the CH type. Thus, choosing the appropriate screen thickness, it is possible to equalize the sensitivity in a wide energy range from $200 \mathrm{keV}$ to $10 \mathrm{MeV}$. However, the main problem of the "broadband" detector is the response matching in the range up to $100 \mathrm{keV}$. As can be seen in Fig.5 (red curve), a significant decrease in sensitivity occurs in this energy range due to absorption of the attenuation of gamma radiation by the screen. Adding a reflector - the blue curve, increases the sensitivity of the detectors in the range of $30 \ldots 300 \mathrm{keV}$ (see Fig.5). The inverse leveling is to add a substrate under the sensitive layer, with the corresponding material and the corresponding thickness. The use of a diffuser screen increases the sensitivity of thin span detectors in the high energy range, however, due to the 
attenuation of low energies, it reduces the response in this area (see Fig.5). To compensate for this effect, special reflecting scattered are used, which improve the response in the energy range up to $1 \mathrm{MeV}$.

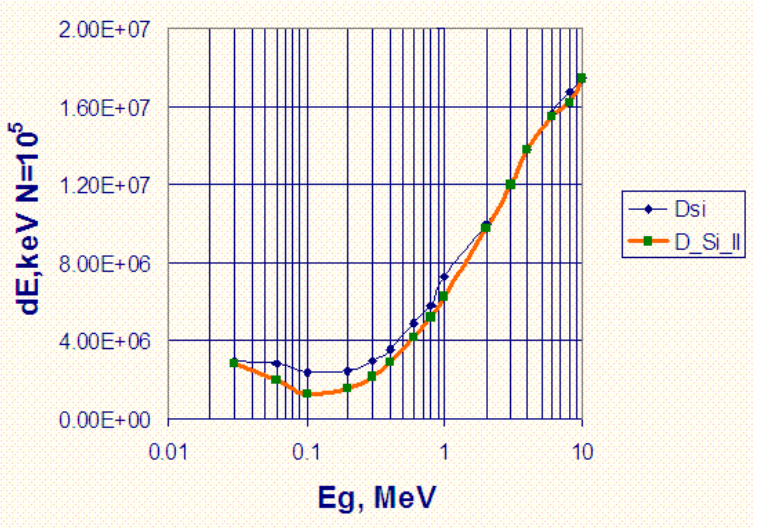

Fig.6. The effect of the substrate on the sensitivity distribution of a silicon detector. Red curve without substrate, blue curve - with a substrate

Using a substrate significantly increases the efficiency in the range up to $1 \mathrm{MeV}$ (Fig.6), while the efficiency remains practically unchanged for higher energies. It should be noted the effect of the invariance of the response for minimum energies $\left(E_{\gamma}=30 \mathrm{keV}\right.$, see Fig.6). While the response formation in these cases have slightly different mechanisms:

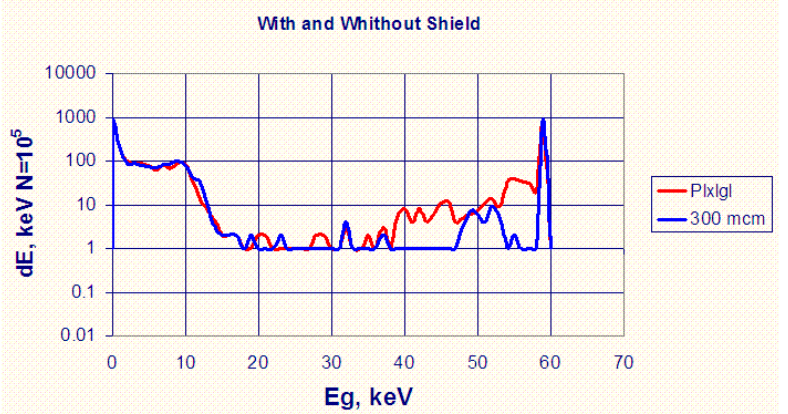

Fig. 7. Scattering of $E_{\gamma}=60 \mathrm{keV}$ passing through a filter $\left(\mathrm{C}_{8} \mathrm{H}_{8}\right)$ of $10 \mathrm{~mm}$ - red curve

The coincidence of the response of the unshielded and the detector using a screen up to $10 \mathrm{~mm}$ thick (Fig.7) explains a weak dependence of the sensitivity in this energy range on the change in the constructs. For energy of $60 \mathrm{keV}$, in particular, this is due to the absorption peak, in the absence of a screen, to the redistribution of the primary energy in the range of Compton scattering.

\section{CALCULATION OF AN AMBIENT DOSE}

The spatial distribution of the absorbed energy in the studied object determines the degree of the effect of radiation, the most dangerous places, which, as a rule, correspond to the maximum energy release. To analyze all these factors, the ambient dose equivalent of $H(d)$ is introduced, which simulates the real effect of radiation on the body. The developed "Doze ${ }_{X}$ " model allows one to obtain the distribution of absorbed energy in an extended object of arbitrary shape. Fig.8 shows the results of modeling the distribution of absorbed energy in silicon $1 \mathrm{~cm}$ thickness.

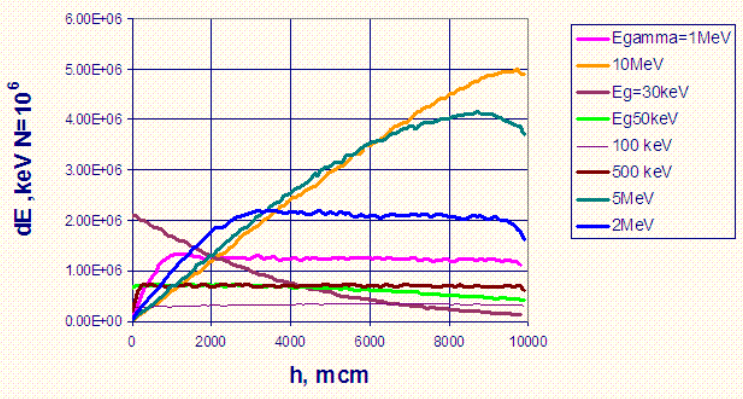

Fig.8. Distribution of absorbed energy in silicon, depending on the primary energy of the gammaquantum

In Fig.8, it can be seen that up to an energy of $2 \mathrm{MeV}$ (blue curve), that the distribution of absorbed energy is almost uniform, starting with gamma quanta energy of $100 \mathrm{keV}$ (red curve). For energy of $50 \mathrm{keV}$ (green curve) at a thickness of $1 \mathrm{~cm}$, the flow attenuates less than twice, but for thicknesses up to $3 \mathrm{~mm}$ the spatial uniformity of energy release is preserved. But if in the energy range $100 \ldots 500 \mathrm{keV}$ the distribution of absorbed energy over a thickness of up to $1 \mathrm{~cm}$ is almost uniform, then already for the energy of $500 \mathrm{keV}$ (brown curve) a certain surface effect begins to play a role, which is associated with a decrease in the probability of gamma-quantum interaction with the medium at the beginning of the target so and with the transfer of energy by delta electrons by means of increasing their runs. Nevertheless, up to energy of $2 \mathrm{MeV}$, uniformity of absorption over the thickness is maintained with a simultaneous decrease in the probability of the interaction of a gamma quantum in thin layers (surface effect). Finally, for energies above $2 \mathrm{MeV}$, the uniformity of energy absorption at silicon thicknesses of the order of $1 \mathrm{~cm}$ is no longer observed, but a maximum appears in the absorption distribution. So for energy of $5 \mathrm{MeV}$, it is observed at a thickness of $8.5 \mathrm{~mm}$ from the surface, for $10 \mathrm{MeV}$ at a thickness of $9.7 \mathrm{~mm}$ from the surface. Finally, the curve for $30 \mathrm{keV}$ shows full absorption in a thickness of $1 \mathrm{~cm}$, as well as the formation of a "surface dose", which is not typical for high energies. It should also be noted that the correlation given in Fig. 8 with the distribution of sensitivity in silicon versus the energy for $1 \mathrm{~cm}$ of silicon shown in Fig.1.

\section{CONCLUSIONS}

An important characteristic of dosimeters is their sensitivity, which in the general case has a direct depen- 
dence on the primary particle energy; in the case of spectral distribution, this dependence can be more complex.

The sensitivity of the dosimeter designed to measure the exposure dose rate is determined by the number of pulses (counts) per $\mu R / h$. When developing a new generation of detectors, adaptation to specific application conditions is necessary. When used in nuclear power plants, the following factors must be considered: prompt $\gamma$ - radiation, $\gamma$-radiation of short-lived fission products, capture $\gamma$ radiation. It is well known that during fission of uranium and plutonium nuclei,7...8 MeV is released in the form of instant gamma radiation and $6 \ldots 7 \mathrm{MeV}$ in the form of a delayed one. Thus, gamma rays emitted by fission fragments should make a significant contribution to radiation energy release. When a thermal neutron is captured by an atomic nucleus of an absorbing medium, the following reaction occurs ${ }^{A} X_{Z}+n \rightarrow{ }^{A+1} X_{Z}$, the so-called radiation capture, followed by the emission of a photon. In this case, the photon energy can reach $11 \mathrm{MeV}$ [9] and must be taken into account in the formation of the radiation environment. For a water coolant, as a result of interaction in the active zone of fast neutron fluxes with oxygen nuclei, the ${ }^{16} O(n, p){ }^{16} N$ reaction occurs. In this case, the formed radionuclide ${ }^{16} N_{7}\left(T_{1 / 2}=7.35 \mathrm{~s}\right)$ decays, emitting gammarays with energies of $6.14 \mathrm{MeV}(68.8 \%), 7.11 \mathrm{MeV}$ (4.99\%), 8.87 MeV (0.062\%) [9]. Also, when characterizing and recording the radiation background, it is necessary to take into account the rescattering of secondary radiation generated during the capture of thermal neutrons in hydrogen-containing protection elements. The developed dosimeter model allows adapting the constructs to the diagnostic requirements of a new generation of dosimeter equipment based on a silicon sensitive element. A possible direction for realizing the task is to use spectrometer mode for determining the absorbed energy by integrating the detector readings taking into account the real spectral distribution of primary flow. The model allows one to take into account the finite dimensions of the detector and thus take into account both the real energy escape by the secondary particles and the effect of backscattering, which allows one to take into account the return of reflected radiation to the detection region, transformation of the primary spectrum transmitted both through the detector's main body and through special transforming screens that allow increasing detector sensitivity in certain energy ranges. It is supposed to solve the task of optimizing the sensitivity of the detector in a wide energy range by taking into account the real absorption spectrum, space energy deposition and determining errors when working in different energy ranges and linking the response to the exposure dose.

\section{References}

1. The CERN Large Hadron Collider: Accelerator and Experiments. V. 1: LHC Machine, ALICE, and ATLAS / Edited by A. Breskin and R. Voss. Geneva, CERN, 2009, 407 p.

2. G.L. Bochek, V.I. Kulibaba, N.I. Maslov, et al. Silicon pad detectors for a simple tracking system and multiplicity detectors creation // Problems of Atomic Science and Technology. Series "Nuclear Physics Investigations". 2001, N1, p.36-39.

3. G.L. Bochek, O.S. Deiev, S.K. Kiprich, O.A. Kapliy, N.I. Maslov, V.D. Ovchinnik, S.M. Potin, M.Yu. Shulika, G.P. Vasiliev, V.I. Yalovenko. Low-energy X-ray radiation after the biological shielding of electron accelerators // Problems of Atomic Science and Technology. Series "Nuclear Physics Investigations". 2018, N3(115), p.172-177.

4. G.L. Bochek, A.V.Kosinov, V.I. Kulibaba, A.A. Mazilov, N.I. Maslov, et al. Charged particles registration in conditions of background irradiation // Journal of Surface Investigation. X-ray, Synchrotron and Neutron Techniques. 2005, N4, p.68-71.

5. V.I. Kulibaba, A.A. Mazilov, N.I. Maslov. On the opportunity of $\beta$-radiation detection by Si detectors in the Chernobyl failure area // Problems of Atomic Science and Technology. Series "Nuclear Physics Investigations". 2006, N3, p.140-141.

6. G.P. Vasiliev, V.K. Voloshin, S.K. Kiprich, N.I. Maslov, et al. Sealed silicon detector's module of ionized irradiation // Problems of Atomic Science and Technology. Series "Nuclear Physics Investigations". 2010, N3, p.200-204.

7. N.I. Maslov. Physical and technological aspects of creation and applications of silicon planar detectors // Problems of Atomic Science and Technology. Series "Nuclear Physics Investigations". 2013, N2(84), p.165-171.

8. I.V. Gordeev, D.A. Kardashev, A.V. Malyshev. Nuclear Physics constants: Directory. Moscow: "Gosatomizdat", 1963, $391 \mathrm{p}$.

9. V.N. Dubina, A.V. Chorny, V.V. Chorny. Problems of remote detection of chemical explosion and fissile by neutron-activation diagnostic method // Problems of Atomic Science and Technology. Series "Nuclear Physic Investigation". 2014, N5, p.69-75 


\title{
МОДЕЛИРОВАНИЕ ОТКЛИКА ПЛАНАРНОГО КРЕМНИЕВОГО ДЕТЕКТОРА ПРИ ИЗМЕРЕНИИ МОЩНОСТИ ЭКСПОЗИЦИОННОЙ ДОЗЫ В ДИАПАЗОНЕ ЭНЕРГИЙ ОТ 5 кэВ до 10 МэВ
}

\author{
В. Н. Дубина, Н. И. Маслов, И. Н. Шляхов
}

Рассмотрены основные преимущества применения кремниевых полупроводниковых детекторов в задачах дозиметрии по сравнению с традиционными детекторами. Проанализированы недостатки и предложены возможные методы их устранения. Один из предложенных методов позволяет увеличить эффективность регистрации гамма-квантов в диапазоне энергий 0,1...10 МэВ. Сформулированы требования, необходимые для оптимизации конструкции детекторов, работающих в широком диапазоне мощностей доз и энергии гамма-излучения, методом компьютерного моделирования. Проведенные математические расчеты и компьютерное моделирование определяют конструкцию дозиметра, материалы и толщину $\gamma$-конвертера. Приводятся механизмы моделирования поглощенной дозы в воздухе и амбиентной дозы в кремниевых детекторах толщиной от 300 мкм, размерами $(5 \times 5)$ мм $^{2}$ и $(1,8 \times 1,8)$ мм $^{2}$, в диапазоне энергий падающего $\gamma$-излучения от 5 кэВ до 10 МэВ.

\section{МОДЕЛЮВАННЯ ВІДГУКУ ПЛАНАРНОГО КРЕМНІЕВОГО ДЕТЕКТОРА ПРИ ВИМІРЮВАННІ ПОТУЖНОСТІ ЕКСПОЗИЦІЙНОЇ ДОЗИ У ДІАПАЗОНІ ЕНЕРГІЙ ВІД 5 кеВ до $10 \mathrm{MeB}$}

\author{
В. М. Дубина, М.І. Маслов, І.М. Шляхов
}

Розглянуто основні переваги застосування кремнієвих напівпровідникових детекторів у задачах дозиметрії в порівнянні з традиційними детекторами. Проаналізовано недоліки та запропоновані можливі методи їх усунення. Один із запропонованих методів дозволяє збільшити ефективність реєстрації гамма-квантів у діапазоні енергій 0,1..10 МеВ. Сформульовано вимоги, необхідні для оптимізації конструкції детекторів, які працюють у широкому діапазоні потужностей доз і енергії гаммавипромінювання, методом комп'ютерного моделювання. Проведені математичні розрахунки і комп'ютерне моделювання визначають конструкцію дозиметра, матеріали і товщину $\gamma$-конвертера. Наводяться механізми моделювання поглиненої дози в повітрі і амбієнтної дози в кремнієвих детекторах товщиною від 300 мкм, розмірами $(5 \times 5)$ мм $^{2}$ i $(1,8 \times 1,8)$ мм $^{2}$, у діапазоні енергій падаючого $\gamma$-випромінювання від 5 кеВ до $10 \mathrm{MeB}$. 